
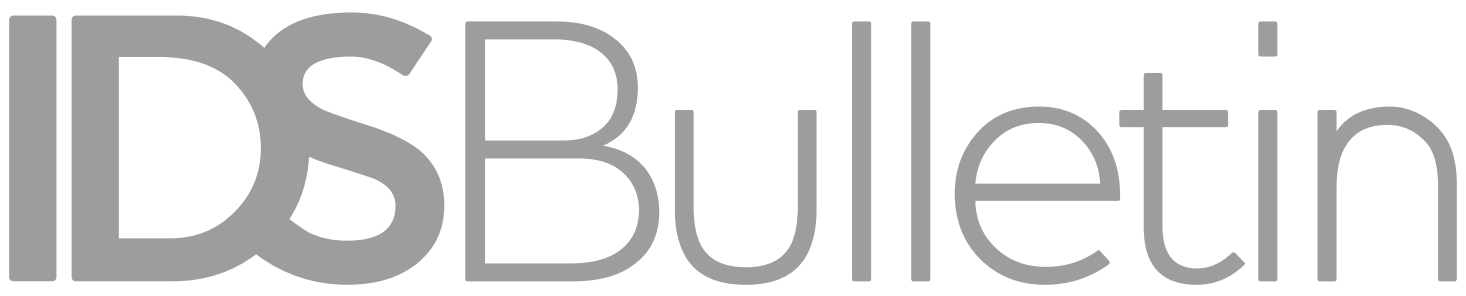

Transforming

Development Knouledge

Volume 50 | Number 1 | May 2019

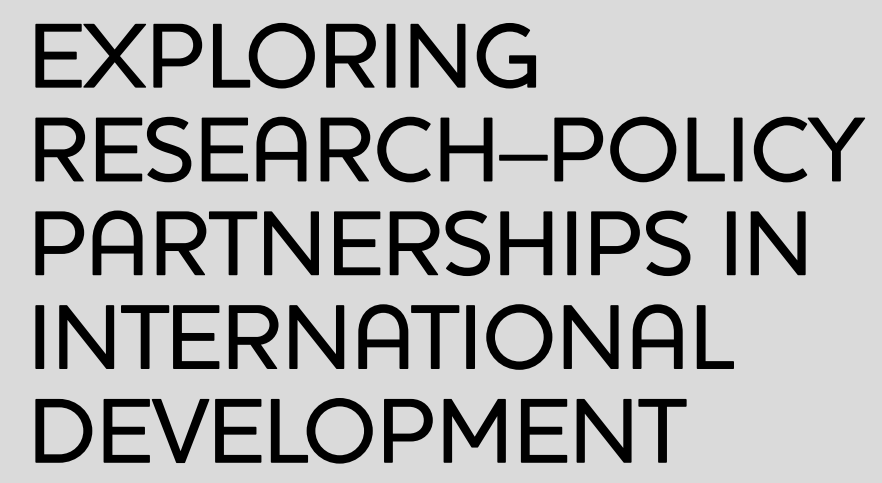

Editors James Georgalakis and Pauline Rose

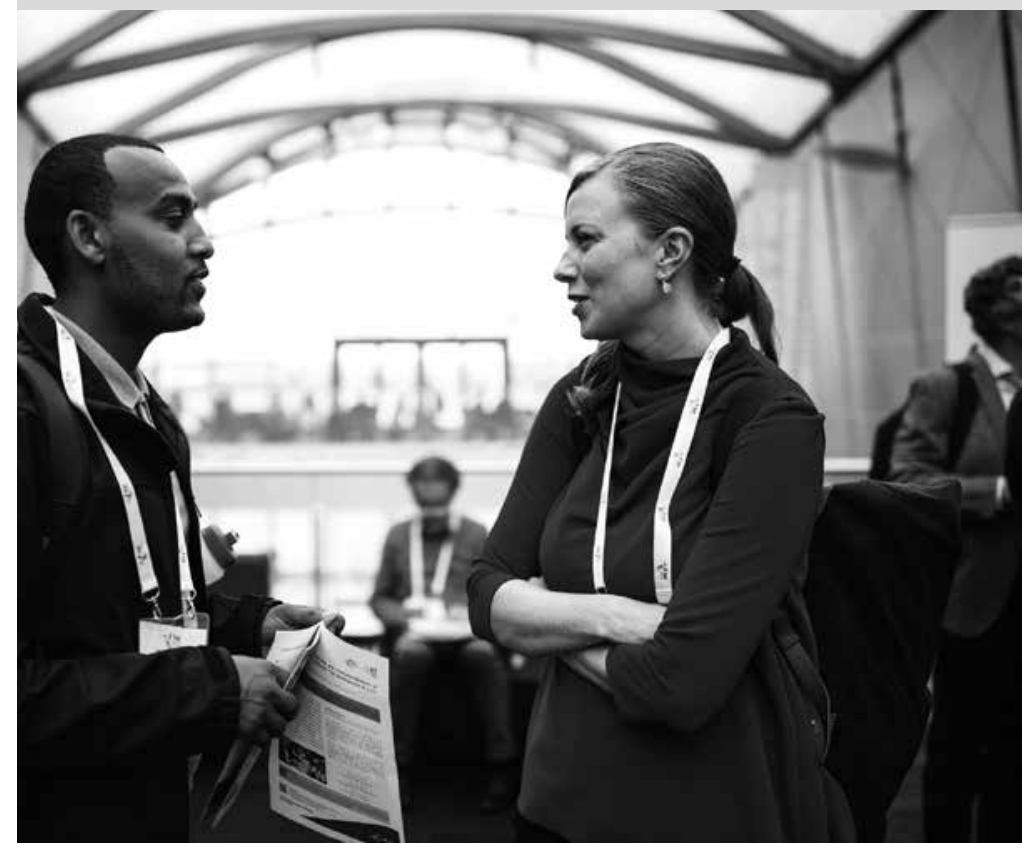


Notes on Contributors

Foreword

Diana Dalton

Introduction: Identifying the Qualities of Research-Policy Partnerships in International Development - A New Analytical Framework

James Georgalakis and Pauline Rose

Rethinking Research Impact through Principles for Fair and Equitable Partnerships Kate Newman, Sowmyaa Bharadwaj and Jude Fransman

Pathways to Impact: Insights from Research Partnerships in Uganda and India Rachel Hinton, Rona Bronwin and Laura Savage

Exploring Partnerships between Academia and Disabled Persons' Organisations: Lessons Learned from Collaborative Research in Africa

Maria Kett, Mark T. Carew, John-Bosco Asiimwe, Richard Bwalya, Anderson Gitonga, Boakai A. Nyehn, Joyce Olenja, Leslie Swartz and Nora Groce

\section{Layered and Linking Research Partnerships: Learning from YOUR World Research in Ethiopia and Nepal}

Vicky Johnson, Anannia Admassu, Andrew Church, Jill Healey and Sujeeta Mathema

Fundamental Challenges in Academic-Government Partnership in Conflict Research in the Pastoral Lowlands of Ethiopia

Mercy Fekadu Mulugeta, Fana Gebresenbet, Yonas Tariku and Ekal Nettir

Regional Research-Policy Partnerships for Health Equity and Inclusive Development: Reflections on Opportunities and Challenges from a Southern African Perspective

Nicola Yeates, Themba Moeti and Mubita Luwabelwa

How Did Research Partnerships Contribute to Bangladesh's Progress in Improving Lives?

Mushtaque Chowdhury

Glossary 


\title{
Layered and Linking Research Partnerships: Learning from YOUR World Research in Ethiopia and Nepal ${ }^{*} \diamond$
}

\author{
Vicky Johnson, ${ }^{1}$ Anannia Admassu, ${ }^{2}$ Andrew Church, ${ }^{3}$ \\ Jill Healey ${ }^{4}$ and Sujeeta Mathema ${ }^{5}$
}

\begin{abstract}
This article draws on learning from the YOUR World Research project in Ethiopia and Nepal, which uses the socioecological Change-scape framework to understand how participants in research need to be understood within a landscape of changing institutional, environmental, and political contexts. The article explores whether trustful relationships, ownership, and commitment can bring about more effective societal change through research. Through group discussion and reflective perspectives, the authors draw out possible indicators of successful partnership from the different contexts in which YOUR World Research was working. These include histories of interpersonal relationships; shared vision and motivations; building ownership; shared platforms and spaces for dialogue; and flexibility to respond to shocks and changes in context. The article suggests that whilst being realistic about the power and politics of partnership, there are mechanisms in partnership models that can help support high-quality rigorous research whilst creating impact at local, national, and international levels.
\end{abstract}

Keywords: youth, power, marginalisation, street-connected, civil society organisations, community, interpersonal relationships, Change-scape.

\section{Introduction}

For many readers of this IDS Bulletin involved in research in the global South, the desire to work with partners to create impact has for decades been a fundamental reason motivating us to undertake research. More recently, however, in the twenty-first century, governments and funding bodies in many Western nations now require social science researchers to provide evidence that funded research has achieved economic and societal impact using specific criteria (Bastow, Dunleavy and Tinkler 2014). This has implications for research partnerships as researchers experience challenges involved in adopting certain practices, often 
prescribed by funders and governments, to achieve, measure, and report on impact.

This article discusses some of these challenges as experienced by the partnerships formed through the process of research in an ESRC-DFID piece of research known as YOUR World Research. ${ }^{6}$ The partners involved in YOUR World Research include universities, both in the global North (the University of Brighton and Goldsmiths, University of London) and in the global South where the national research leads have institutional links (Addis Ababa University and Tribhuvan University). Also included is the civil society organisation (CSO) ChildHope UK and a national non-governmental organisation (NGO), CHADET, which supports applied research in Ethiopia, as well as ActionAid Nepal and a small organisation called HomeNet, also in Nepal.

Youth Uncertainty Rights (YOUR) World Research (the popular title for the ESRC-DFID-funded research) is about how marginalised youth navigate uncertainty and negotiate their rights in conflict-affected and fragile environments in Ethiopia and Nepal. National research teams worked with 500 youth in each country and carried out co-construction of methodology in the early participatory phase of the research. In later phases, across four rural and urban research sites, detailed in-depth interviews were conducted with 150 youth, and then focused interviews with a further 100 youth on particular emerging issues of importance to young participants in each country. Regional/provincial and then national youth seminars were then held in order to verify youth perspectives and feed youth evidence and voice into policy and practice. This article discusses how the partnerships in YOUR World Research in both Ethiopia and Nepal have proved to be platforms from which to amplify the voices of marginalised youth to achieve impact.

In this article, the directors of our key CSOs and the Principal Investigator (PI) present reflective perspectives on their experience of partnerships. We use these perspectives as one source of material alongside the discussions that partners recorded in a focus group to analyse the common threads in our analysis of partnership. The focus group involved partners from universities and CSOs in the UK, Ethiopia, and Nepal coming together face to face and following up remotely. We drew diagrams of relationships, defined questions to dig deeper, and recorded our discussion. To facilitate and fully represent partner voices in the text, each civil society partner was asked to consider the PI's perspective and the findings from the focus group and then in the perspective presented in this article to outline their motivations for involvement in research, indicators of good partnership, and some of the significant challenges to partnerships in supporting research to be impactful. Each partner considered a central question in writing their perspectives that emerged as a key issue in the focus group discussions: whether partnerships aiming to achieve impact require trustful relationships, ownership, and commitment to action to bring about societal change? In brief, through focus group discussion and commenting on each 
other's perspective, we agreed that our shared motivation behind the YOUR World Research, from all partners, was ultimately to improve the lives of the poorest and most marginalised. Our initial discussions indicated that we also agreed that the basis of successful partnerships for impact lay in the interpersonal relationships, common goals, and shared vision we discuss below.

We present information about how our different global and local partnerships were formed and what different partners feel has contributed to success. In our analysis and our conclusion, we link these reflections on partnership to our conceptual framework, Change-scape (see Section 2 for description and references). We discuss how this has helped us to build and sustain partnership by putting in place space for dialogue, mechanisms, or strategies such as team sharing, sustained communication, and support between global North and South, alongside securing funding that enables us to build on previous interpersonal and institutional relationships. Approaches to partnership and applied research have, as well as maintaining our initial intention to involve marginalised youth in applied research, proved successful in achieving impact in rapidly changing political and environmentally fragile environments.

Working with the Change-scape framework, we have been able to draw out partnership indicators and mechanisms in this article, and these are offered as ways to achieve better partnerships and impact. Involving youth and communities in the global South in developing the conceptual framework is an approach that aligns with findings of projects examining partnership-based research undertaken in the UK. Proponents of a community approach to partnership that works on a basis of coproduction argue that involving community partners and people in all stages of the research lifecycle, including design and conceptual thinking, allows research partnerships to challenge existing power relationships and make a difference to the communities of geographies, identity, and interest that are connected to the research (Banks et al. 2019; Martikke, Church and Hart 2019).

\section{Change-scape - an approach to building partnerships for applied research}

A distinct aspect of this article is that we offer insights into how the conceptual framework that we use in the overall approach to our research and impact helps us to both work in this fast-changing environment and keep our focus on the children and young people we are working with. This framework we refer to as a Change-scape (from Johnson 2011, 2017, for example), a landscape of change that is in constant flux and that is changing over time. It is a socioecological model, informed also by critical realism (for example, as expressed by Robson 2002), that places people/youth at the centre of research. In keeping with a critical realist approach, a series of mechanisms is suggested to build the agency of research participants and researchers to interact with other relevant actors in different contexts to create impact. 
The Change-scape has, therefore, in YOUR World Research given us ways to link the young people at the centre, who have multiple and shifting identities, ideas, and interests, with the broader social norms and power dynamics in families and communities, and in turn with often fast-changing broader natural, cultural, political, and policy environments. The article argues that this conceptual framework has been key to YOUR World building more collaborative and impactful research together, as the people in partnerships are embedded in the research. We also suggest that these mechanisms in our applied research clearly link to partner motivations to facilitate changes in the lives of marginalised youth and in their broader contexts.

Change-scape, as employed by YOUR World Research, includes mechanisms such as: creating safe spaces for youth, as well as researchers and partners working with them to develop confidence and to interact with policymakers; strategies of communication across the research partners to share learning and build capacity; and continued communication to build trust between people involved in the research. Partners have discussed in their reflections below on how we have worked together to achieve meaningful and transformational changes in young lives and in the families, communities, and societies that they live in.

Impact is also understood beyond direct changes in young lives, at the following layers or levels: the policies and practices of partners with whom the project formed trusted relationships; policies of broader stakeholders interacting in the research including government and non-governmental service providers; and in informing rights advocates amongst youth, in communities and civil society for transformational societal impact. This notion of impact being layered fits with a socio-ecological Change-scape framework that recognises youth as agents of change in constantly changing contexts, as described above (Johnson 2017).

We go further to then ask, on the basis of the partner discussions and perspectives presented, how these fit with or extend our Change-scape. We discuss in this article: how we have established trust and achieved shared motivations for research; what mechanisms or strategies have been useful for building our partnership; and how this has translated into different outcomes and impact. All of the partners appreciate that we have our own different personal, organisational, social, and political agendas that layer on top of this desire to achieve transformational societal impact that can help young people to realise their dreams and attain better futures. Working with marginalised youth enabled the team to better understand their views and to feed these into a research process that aimed to have impact. To what extent youth were treated as partners or participants in the process is not discussed (see, for example, Johnson et al. forthcoming, 2019). In this article, we keep the focus on how partners in CSOs in both countries have worked together with researchers to engage young people and change their contexts and lives. 


\section{Different perspectives on partnership}

We write this section from the different perspectives of the partners in YOUR World. Each reflective perspective below was written by individuals, using a set of headings agreed in discussion by the project team. Although we talk about all being part of a broader YOUR World partnership, in reality the partnership comprises many layers and formations of relationships that are older or newer, and are in different stages of building trust and shared values. The reflective perspectives set out below first include the PI, from a UK university base. We then provide two perspectives from the global South, one from two NGO partners linked to YOUR World Ethiopia and one from our NGO partner from YOUR World Nepal. These describe the way in which partnerships formed between this team and the research teams linked to universities and NGOs in the global South.

The perspectives of the NGO partners focus on what motivated them to be involved in the research project and how their partnerships have developed with research teams that are based in their offices and working with them to achieve impact. These draw out indicators and mechanisms for achieving what we see as a good partnership and impact. They also reflect on the importance of the spaces that we have all created for South-South learning and the South-South partnerships that have strengthened through the period of YOUR World Research. Finally, we provide a reflective perspective from our Ethiopian NGO partner who specifically discusses how partnership has informed impact.

\subsection{The reflective perspective of the $\mathrm{PI}$}

As a practitioner researcher for over 20 years before entering academia, my research has always needed to feed into policy and practice. So for me the impact agenda was welcome. I have gained important learning from within academia and now as a PI for YOUR World Research, funded by ESRC-DFID's foint Fund for Poverty Alleviation Research. Beyond instrumental impact where we seek to change policy and practice and impacts on capacity building and networking, conceptual impact is vital. Conceptual impact is about creating new knowledge and insights that help us to leap over challenges in the reality of poverty and to negotiate different pathways out of poverty together.

I see partnership and impact as happening in a Change-scape or landscape of change, in rapidly evolving political, fragile, and conflict-affected environments, changing social norms, and global and national economic and political systems. And with this, changing commitments to different potential pathways out of poverty. Processes of building partnerships also link to the shifting and multiple identities of the people we conduct our research with, but also to our own shifting situations and identities as researchers. All this is set within a complex network of relationships and connections, inside and outside specific research processes, some positive and some negative, which are then sometimes built into partnerships that can facilitate impact. As in our research, we need to navigate uncertainty in a positive way together. 
Partnership includes negotiating power dynamics, acknowledging different agendas, and a commitment to each changing ourselves. To listening to each other, sharing values, and collaborating on approaches to working with poor and marginalised people. It is a two-way or multi-way set of relationships and dynamics. In YOUR World Research, it is not just about changing the context in which youth live their lives, but creating conditions that enable young people to change their own contexts. I cannot imagine how this would be possible without strong national organisations that have trusted relationships with marginalised youth, without which we could not even carry out our research. They work tirelessly to change not only their own programmes, but also to influence thinking amongst other local services and provincial and national youth policy.

This reflective perspective, along with research team discussions, have helped us to structure this article. We have used perspectives from partners in Ethiopia and Nepal to draw out indicators and mechanisms for achieving better partnerships. Understanding the layers of partnership working in different contexts and the way in which individuals interact within their institutional power dynamics is similar to our approach to our research in the Change-scape conceptual framework. We draw out indicators and mechanisms that help to link researchers and practitioners in partnership to the institutional and political systems that surround them. Part of our person-centred approach to research and creating impact through the Change-scape framework links people in research processes into partnerships and into broader social, cultural, environmental, and political environments.

\section{Reflective perspectives from partners}

Through initial discussion at a workshop organised by the ESRC-DFIDfunded Impact Initiative at the Institute of Development Studies, we noted our different layers of partnership, and that partnerships are built over time. We decided to reflect further and planned for partners to write reflective perspectives from Ethiopia and Nepal from which to draw out indicators and mechanisms for building better partnerships. Partners from the two countries examined the way in which partnership has been formed and asked the question: Do partnerships require trustful relationships, ownership, and commitment to action to bring about societal change? We did not have a set format for these perspectives, but more of an open forum so that indicators could emerge and then we could further analyse to draw out key mechanisms that would be useful to share for broader learning.

Our key assumption in all of these discussions was that partnership had been important in achieving impact in the YOUR World Research project. When interrogating this, we decided that partnership had served as a platform from which marginalised youth views on their strategies to navigate uncertainty could be at the core of impact. In turn, by working with broader stakeholders, the research had informed policy and practice and this was seen as a step towards transformative impact in youth lives and their communities. 
Evidence has been collected throughout the project that demonstrates impact in a number of different contexts. For example: the academic capacity of researchers from the global South has increased, demonstrated by progress in doctoral studies; local partner policy papers and how they define the most marginalised has been influenced by the research project; research into policy and practice seminars on discourses around youth and marginalisation have been set up with national universities and ministries in both countries. Relevant government ministries in each country are engaging with the research partnerships and have asked for evidence about marginalised youth to feed into particular papers on the status of youth and of youth policy. There have also been spaces created for discourse between policymakers, practitioners, marginalised youth, and researchers in YOUR World and in the broader national academic community. For example in both countries, ministries have been keen to work with YOUR World national research teams on provincial and national youth seminars to understand how youth voices can feed into youth policies (in March 2019).

\section{What are you looking for in partnership? Indicators for positive partnerships}

The partners have identified indicators of success for building partnership that we feel have been critical to making our academic research more applied. In this section, we provide two jointly written reflective perspectives based on discussion and co-writing between the authors. The first is an example of South-North three-way partnership and describes how this partnership was established between YOUR World Research team and donors, the UK-based NGO ChildHope, and the Ethiopian-based NGO, CHADET. Both ChildHope and CHADET work on child rights and poverty. ChildHope facilitates funding from UK-based donors and provides capacity building and sharing of knowledge with national partners, such as CHADET.

The second joint perspective is built on a long-standing South-North relationship between ActionAid Nepal and the PI in which there has been a research relationship for over 20 years. ActionAid Nepal is now a national Nepali charity that arose out of the international NGO, ActionAid. This second perspective also focuses on the South-South partnership that has been built during the research process between the national YOUR World Research Nepal team and the national NGO, ActionAid Nepal. The two perspectives reflect on the network and history of trust through interpersonal relationships. From the reflections, we have further analysed and presented an emerging set of indicators that are key components of positive partnerships and impact.

\subsection{Reflective perspective from ChildHope and CHADET (Jill Healey, ChildHope and Anannia Admassu, CHADET)}

The 'web' of links between the universities and agencies involved in this partnership are complex and have evolved over time. CHADET and ChildHope have worked in partnership since 2001, and both organisations have evolved 
and grown over that time. Both were established as an immediate response to the visible street and working children in mostly urban settings, focused on meeting core needs and survival - food, shelter, clothing, first aid, and basic health care as well as to enhance the active participation of communities and other stakeholders in the protection of vulnerable children. As each organisation came to understand the children better, the focus extended beyond the immediate, looking at education and training, life skills, and basic psycho-social support.

The children and young people were increasingly consulted about their situation as both CHADET and ChildHope developed awareness of the importance of children's participation in explaining their problems and identifying solutions. This in turn led both organisations to start considering the causal factors behind street involvement. What pushed or pulled children to the cities from their (usually rural) homes? Did they attain the opportunities they had hoped for when they arrived and, for those who wanted to return home, was reconciliation with their parents, families, and communities possible? CHADET and ChildHope began to explore the feasibility of preventive strategies, so that children were less tempted to take the risks of making such hazardous and uncertain journeys and saw opportunities in their home villages.

As the thinking grew, so too did the size and scope of both organisations, both recognising the potential to reach many more children and young people, while maintaining a focus on those at very high risk. They were also aware of the danger of operational growth if this wasn't matched by strengthening the infrastructure underpinning activities. The nature of the partnership had always been one that had been aware of - and discussed - the fragile power dynamics between 'Northern' and 'Southern' partners. Both had witnessed the problems faced by Southern organisations that had delivered large projects devised and funded from the North only to be left with inadequate infrastructure unable to sustain projects independently when the money for the project dried up. Unfortunately, the drive towards large-scale, results-driven development popular with major donors in the early to mid-2000s offered little choice to many agencies.

ChildHope and CHADET were fortunate to receive a six-year strategic grant from Comic Relief in 2006, which enabled them to simultaneously grow the reach of CHADET's programmes and give the attention and resources needed to strengthen internal policies, systems, and structures. This in turn prepared the ground for the two organisations to secure UK Aid Girls Education Challenge (GEC) funding in 2013 as part of the fund's 'Step Change' programme. The funding was the largest single grant secured in each of the organisation's history and ChildHope was a much smaller lead partner than the others in the programme (Save the Children, Plan, Mercy Corps, Aga Khan Foundation, Care International, etc.).

It would be fair to say that the experience of managing this programme, now in its second phase - itself intensely results-focused with heavy compliance requirements - has both tested and strengthened both organisations and the relationship they have with one another. It is important to describe the long journey that the two organisations have taken together to get to this point because 
it illustrated not only their shared and evolving vision for the children and young people they work with but also the commitment to the partnership and the organisations themselves. Over a period of almost 20 years, they have built a strong platform that enabled the Ethiopian component of the YOUR World Research project to be developed.

Importantly, this platform was not only made up of policy and processes but also of people and time. Vicky Johnson, PI and lead of YOUR World Research, had previously worked for ChildHope as Head of Partnerships and Programmes and was therefore well known to both organisations, as well as supporting CHADET's Director to take forward his aspirations to study for a PhD. The limited funding available for the YOUR World Research, combined with some of the delivery requirements and expectations of the grant, would have made it very difficult for CHADET to participate in the research as a standalone project. Similarly, ChildHope would not have been in a position to support CHADET, or any other partner, if this were their only piece of work together. However, by building on existing resources, connections, and infrastructure, and working with people who knew each other well, the Ethiopian component could be co-created by drawing on the strengths of its different participants and what they could bring to the table.

From that base, further essential elements could be brought in as part of developing impact - experts from academia and government officials, for example - essential to the effectiveness of the research. Moreover, access to communities and ability to identify and work with the young people involved was made possible by the fact that the project was being run by an organisation with recognised integrity and understanding of the community, and known to deliver quality support to children and young people living in high-risk and hazardous contexts. That this organisation was coming to talk to the young people about their aspirations and rights was likely to be much less threatening and seen as a logical step in the organisation's programmes.

To make the partnership work in a research context and to create impacts, the relationships needed to be adjusted. ChildHope, often a lead partner, took on a more facilitative 'back seat' role. This meant quite significant involvement in the setting up phase, a much lower profile during implementation, and increased involvement again as the project closes. The ongoing GEC programme, still being implemented by CHADET and ChildHope, will enable the research partners to explore potential application of the learning in different contexts, as there is continuity of connection between them.

As a local implementing partner, CHADET has been able to establish new partnerships and widen its existing reach for impact with government bodies and other institutions at local, regional, and federal, i.e. ministerial offices. Over the latter stages of the project period, there have been fast and fundamental changes in the Government of Ethiopia with the inspired new prime minister asking for policies to be redeveloped, and in turn the Ethiopian YOUR World Research team being invited to comment and help develop policy at national level to include the most marginalised youth perspectives into youth status reports and youth national policy. The team has also been asked to set up a research into 
policy and practice forum by the former Ministry of Youth and Sports. This builds on CHADET's experience of setting up a similar forum for children's evidence to influence the Ministry of Women and Children's Affairs.

\subsection{Reflective perspective of ActionAid Nepal (Sujeeta Mathema and Vicky Johnson)}

This perspective demonstrates another layer of relationships and reflects on the South-South partnership between the YOUR World Research team and ActionAid Nepal. It presents how this partnership has formed during the research process and then how it serves as a platform to work with government and international players on issues of youth marginalisation and rights.

In Fune 2016, ActionAid Nepal took up the opportunity to work with the University of Brighton and then later Goldsmiths, University of London, as a research partner on YOUR World Research. With other Southern partners in Ethiopia, the then Director of ActionAid Nepal, Bimal Phnuyal, provided input into the proposal to ESRC and DFID, helping to shape the research and provide details about the context, and where and how to access the most marginalised youth. The research is about youth, their motivations, their desires, their hopes and aspirations, and their uncertainties. ActionAid is keen to learn and understand more to implement effective work to bring changes in young people's lives and livelihoods.

ActionAid Nepal is a non-governmental, non-denominational, non-partisan, and national social justice organisation, rooted and working locally in different parts and regions of Nepal. We are also a part of both national and global social justice movements and other civil society networks, alliances, and coalitions. Shaped and driven by our values, vision, and mission, we work for transformative and structural social changes through people's active agencies. We believe in human rights and embrace human rights-based approaches to fight against not only the symptoms but mainly the structural causes of poverty, injustice, and inequality. In alignment with this, the YOUR World Research project took a rights-based approach that used the Change-scape which links youth voice and agency to our rapidly changing political and environmental context in Nepal.

As the Nepal team of Youth Uncertainty Rights (YOUR) World Research were progressing in their research process, ActionAid Nepal wanted to ensure that the research approach and emerging findings as part of the impact process were shared with the rest of the organisation and its members and networks. It was important to set up regular meetings in order to understand YOUR World findings, and how in response, ActionAid Nepal could change its strategy and approaches where relevant. By being fully informed, different members of ActionAid took ownership of the outcome and amplification of the results, something that ActionAid Nepal regards as an important part of partnership.

The YOUR World partnership between academics and practitioners has brought a vibrant interest in the organisation. In mid 2017, when ActionAid Nepal was in the process of formulating its Country Strategy Paper, a debate took 
place on the centrality of recognising young people/youth and actions needed with them to improve their lives. This youth-centred approach is characterised by the Change-scape that places youth at the centre of YOUR World Research and at the centre of any action that seeks to improve their lives in the midst of intergenerational relationships and cultural, political, and environmental contexts.

Suggestions came from each corner of the organisation about the value in recognising young people as the driving force and energy to bring the changes in our communities. Therefore, it was decided that ActionAid Nepal would work with young people, while keeping women and girls at the centre, amongst all the people living in poverty and exclusion. As a result of this debate that was informed by YOUR World Research, ActionAid Nepal's strategy now clearly and explicitly talks about working with young people and recognises them as change agents/change makers.

In our work on YOUR World Research, we felt it was equally important for academics to initiate a knowledge-sharing process. ActionAid Nepal, with the team of YOUR World researchers, worked to build on the partnership the lead researcher in Nepal had with Tribhuvan University - specifically with the Research Centre for Education, Innovation and Development (CERID). The intention was to facilitate the critical discourses on alternatives in youth education and training, and to advance young people's propositions towards a just and democratic system that will promote a more dignified life. Political spaces were created around these discourses for practitioners, educators, academics, CSOs, and for all those who wanted to debate social justice through movements, and to promote young people's rights. These platforms are spaces where the findings of the research processes, such as YOUR World Research, can influence and create critical mass to fight for justice and democracy.

Social research needs to have action-orientated processes embedded so that research impact can feed into solutions that are sustainable. For any kind of sustainable transformative change, it is important to work at different levels of policy and to work towards young people-friendly policies. In this way, implementation will be more youth focused and impacts longer lasting. Hence, partnerships between academics and practitioners are very vital in terms of sustainable development.

\section{Lessons learned to draw out indicators and mechanisms to improve partnerships and impact}

Lessons learned from the focused discussion recorded between partners and the three perspectives above demonstrate the importance of partnership and impact of interpersonal relationships in building trust, either through experiences of working together over periods of time or by ensuring regular face-to-face meetings.

In both countries, there was also an emphasis from partners about how shared motivations for research were a basis for good partnership. If different researchers and practitioners in organisations have common goals and shared vision, in this project about youth rights and social justice, then there was more likelihood that a partnership could be built 
or grow in strength. The sustainability of funding in order to build long-term interpersonal relationships and institutional partnerships was also raised in both countries. For example, in Ethiopia, the reflective piece by ChildHope and CHADET suggests that organisational growth and maturity due to long-term funding was important for building experience and allowing agencies to engage in partnerships more confidently and effectively.

It was also suggested by NGO partners that if there is an understanding that research has the potential to achieve impact, then the partnership between researchers and practitioners can be stronger. In YOUR World Research, due to the history of the PI as a practitioner for many years, this helped in forming the initial partnership. Although in theory, NGO partners wanted to support the research, at first they did this to varying extents; individuals had to be convinced of the value of the research as opposed to, for example, long-standing intervention strategies or participatory action processes that were seen as an alternative to different forms of research in communities. YOUR World Research had elements of co-construction and participatory action research combined with larger-scale qualitative research which helped different people across the NGOs to come on board with the evidence presented. It was most effective when presentations were given and regular meetings with different teams in NGOs were set up. It also helped when teams visited each other, the Nepal team to Ethiopia, and vice versa. This approach fits with the Change-scape process in that teams, whilst understanding their particular contexts, can share in mechanisms or strategies for ensuring that their research engages with youth and ultimately achieves transformation change. They felt that learning from each other in a very practical way was part of building trust, shared approaches to applied research, and pathways to impact.

Platforms and spaces for discourses and dialogue with research participants, service providers, and policymakers built together by researchers and practitioner partners proved to be effective and to make the research impactful. These spaces that link researchers, and indeed the youth that we work with, to decision makers in communities, service providers, and local and national policymakers are key mechanisms suggested in our Change-scape that was applied in our research. When these platforms and spaces for dialogue were set up early in the research process, they helped to engender interest and ownership of the research findings. For example, a national reference group of academics, policymakers, service providers and, in Nepal, leaders of youth movements and media met throughout the process. An initial meeting was set up during the planning phase to engender ownership and encourage interest in the findings.

By working together in a broader network or sea of relationships, different policymakers and service providers felt part of the process (as suggested by Johnson 2017). The partnership between YOUR World team researchers and partners grew through this process of creating 
participatory spaces, and strong relationships have also been formed with other stakeholders such as government; for example, between the research team, CHADET, and different government ministries and organisations concerned with youth in Ethiopia (see Section 7.1). As also suggested by Morton (2015), research users have a deep understanding of context and are significant players to involve in research processes to achieve impact.

Due to the fast-changing fragile environment and political systems in both Ethiopia and Nepal during the project, the teams and partners had to be flexible and respond to local and national events. This relied on the trust that had been built through interpersonal relationships between the PI and the partners so that the UK team listened to the wisdom of when and where to carry out research. Plans had to change constantly. The Change-scape, applied as a conceptual framework, helped all the partners to pay particular detail in their research design to changing context, and the project trusted the partners and national teams to respond to these changes in as flexible a way as funding allowed. The uncertainty in context was not limited to the global South and changes of positions of researchers in the UK also relied on trust from Southern research teams and partners.

The team has, however, worked together and has been able to be flexible; for example, in Nepal, changing focus from national to provincial decision making at government level due to changes in government structures. The YOUR World Research team in Ethiopia has responded to requests from their new government to comment on and contribute to the annual youth status report and to include the voices of the most marginalised youth in the development of their new youth policy. The Director General of Youth Participation in Ethiopia is collaborating with the research team to involve marginalised youth in national seminars as a way of enabling them to impact on national policy. In a similar way, provincial government is collaborating with the YOUR World Research team in Nepal on provincial and national youth seminars to influence policy most effectively. Such flexibility to respond to political and policy context and new opportunities has been supported by the qualitative and explanatory nature of the reporting for the fund, and also the emphasis from both ESRC and DFID on making research impactful.

To summarise, some of the indicators of good partnership that YOUR World Research partners have drawn out of the project data analysis and reflective perspectives are as follows:

- A network/history of interpersonal relationships formed together;

Shared motivations for research;

Shared visions on political issues of youth rights and social justice as goals of development;

A belief that research is important to inform policy and practice; and 
Ownership of the research process and findings by partners so that they are confident to amplify impacts in their own programming with marginalised children and youth, in new bids to donors, and in advocacy work to influence provincial and national youth policy.

The kinds of mechanisms or strategies that fit with our Change-scape approach and also make our research applied and supportive of our goal to achieve transformation are as follows:

- Meetings to share approaches between partners in the global South and North whilst still paying attention to how the research and impact initiatives would be applied differently in order to respond to particular contexts;

Platforms and spaces for dialogue and discourse based on research created together to agree findings and discuss potential impact with participants of the research, including youth, and a broad range of decision makers and policymakers;

- Flexibility to respond to shocks and changes in the environmental, institutional, and political contexts;

- Continued contact, remote and face-to-face mentoring, capacity building, and communication to ensure trust is maintained and issues resolved; and

Sustained sources of longer-term funding and support to build interpersonal and institutional relationships that form research partnerships that can lead to impact.

These mechanisms or strategies for making research more applied were identified in the perspectives above and through our analysis, and is the kind of practical learning that we think is useful to share in this collection of articles. From the beginning of the research process, there were relationships built between individuals due to co-construction of the proposal and design of the research. It was also important to jointly develop budgets and accountability measures specifying how to manage resources. In this way, when there were any contractual delays or misunderstandings about finances, there was a common starting point for discussion and processes that had been agreed upon.

It was noted in the partnerships that there was growing trust through the research process by ensuring regular face-to-face meetings and, when this was not possible, remote meetings. For example, the NGO partners in Nepal set up weekly meetings with the team. Communication systems were also a priority so that all team members and partners were on the same page. As also mentioned above, which is an indicator and a mechanism, spaces and platforms were created for discourses with service providers and policymakers locally, nationally, and internationally. The project originally planned to involve service providers at local and provincial level; set up national reference groups; 
and have South-South sharing with the all-team inception meeting held in Nepal, the all-team analysis meeting in Ethiopia; and the dissemination and research uptake in the UK. These forums were found to be important, both for ownership and research uptake for broader stakeholders, but also to build the strength of the partnerships.

Throughout the process of the research, the team has also sought further funding from new opportunities that arose; for example, national youth seminars held with broader stakeholders in Ethiopia and Nepal, and partners travelling to present and further collaborate on impact, supported by the ESRC-DFID-funded Impact Initiative and by ESRG and DFID. At a conference to celebrate the ESRC-DFID joint fund in Delhi, both country teams also made new partnerships which are building: in Ethiopia to mainstream disability into inclusive policies in sub-Saharan Africa (see Kett et al., this IDS Bulletin); and in Nepal with a project working with youth, sport, and culture.

\section{YOUR World/CHADET partnership as a platform for creating impact}

This section presents a reflective perspective that helps to understand one of the layers of the multifaceted partnership of YOUR World Research. The perspective demonstrates how strong partnership can help us to learn from youth about their strategies to navigate uncertainty in their lives, to create more impact by supporting them instead of acting on adult assumptions about their lives. It also shows how research can lead to transformation of programmes, policy, organisational attitudes, and behaviour and eventually societal change. The motivation for CHADET and researchers from YOUR World Research is the transformation of marginalised youth lives, communities, organisations, researchers, and the broader context. This is ambitious but this section provides details of how steps towards this are being achieved through partnership and by sharing our experiences of partnership in YOUR World Research with others.

\subsection{Reflective perspective of CHADET (Anannia Admassu)}

The research, in the case of CHADET, has helped to strengthen its existing relationship with the Technical and Vocational Education and Training (TVET) agency, a government body that focuses on skills development of young people. By demonstrating how we've listened to the views of young people, we are now able to make plans to develop new projects jointly, at local and regional levels, attracting other institutions and stakeholders to be part of these efforts.

The nature of the research has demonstrated the benefit of pulling together expertise and collaboration between agencies that are involved in carrying out research with children and young people. This was particularly found to be important for establishing and strengthening new partnerships and for sharing learning from the findings of the research that is being undertaken by other agencies. For example, both the Population Council and the Young Lives study in Ethiopia have joined the TOUR World Research national reference group and collaborated in the research into policy and practice seminars. 
YOUR World Research has also had an impact on CHADET's implementation projects. This research undertaking is timely and instrumental for both CHADET and ChildHope in that learning will contribute to the development of new programmes to address the needs of children who are transitioning from childhood to adulthood, taking into account the local context. We will build stronger child-centred approaches like the Change-scape into projects to make sure they take children's voices, their interaction with adults in communities, and their changing political contexts, into account. As CHADET and ChildHope are both recipients of current funding from DFID to implement a project designed to address the educational needs of tens of thousands of vulnerable girls, we will look at applying the findings of YOUR World Research to that live project, too.

CHADET is looking at how best to make use of academic research to improve their work in the future through initiating collaboration with institutions, for example local universities, to undertake studies of a similar nature.

In countries such as Ethiopia, the relationship between the government and civil society organisations has been characterised by lack of trust and a limited level of collaboration. The fact that CHADET is part of this youth-centred research has helped it to provide evidence and hard facts that have convinced the government to better understand the challenges and prospects of its policies towards young marginalised people in the country. The Change-scape has helped to link youth voices to this changing political context so that young people can be seen as agents of change.

When the doors are closed, you have to use the windows to get in!

Now with the new government in Ethiopia, there is even more opportunity to work together in partnership and create impact. The recently formed Ministry of Women, Children and Youth [formerly the Ministry of Women and Children's Affairs, and the Ministry of Youth and Sports] is now also collaborating with YOUR World Research and CHADET on the final youth seminars for the project and in redeveloping its youth policy.

CHADET has an opportunity to use its existing networks, for instance, the Consortium of Civil Society Organisations in Ethiopia, to disseminate the findings of YOUR World Research in different platforms and working groups across its operational areas.

There is also a better chance for creating impact by strengthening networks and exchange of skills and knowledge between higher learning institutions in Ethiopia with that of the UK.

\section{Conclusions across the partnership}

The key points that we have tried to illustrate through partnerreflective perspectives answer our question: Do partnerships require trustful relationships, ownership, and commitment to action to bring about societal change? The indicators and mechanisms we have drawn out in the article and summarised below, along with growing evidence of impact (for example, provided in the CHADET reflective perspective) suggest that the 
answer is yes. From the perspective of YOUR World Research partners, these indicators and mechanisms were what we regarded as important to both keep the research going in challenging political and fragile environments, and to make steps towards achieving our shared goals of transforming youth lives.

A key indicator was that the partnership has many layers which consist of interpersonal relationships that need to be fostered, nurtured, and sustained. This may be through the experience of working together over time when trust is gradually built, but in new relationships, in order to build trust, space and resources need to be incorporated into bids. The related mechanisms included face-to-face meetings within organisations, between organisations, and between country teams, for example, so that the researchers and partners can establish trustful ways of working together. Indicators of good partnership include interpersonal relationships alongside shared values and visions about development.

Fitting with our conceptual framework of applied research, Change-scape, good partnerships in fast-changing political and environmentally fragile contexts also require mechanisms that enable people, projects, and funding to be flexible and responsive to changing institutional, environmental, and political situations so that research can be carried out safely and effectively, but also so that teams can take unexpected opportunities to create impact such as those arising from a change of government in Ethiopia. These have arisen throughout YOUR World Research in times of rapid political change, and as relationships and trust with broader stakeholders grows as they get to know researchers and partners and see the research findings. Partnerships emerge, develop, and grow as research projects progress and they therefore need to be able to respond in the anticipation of bringing about impact. Indeed, in both the countries involved, Ethiopia and Nepal, significant changes in national and provincial government provided an opportunity for the partnerships to impact on societal change through new and emerging policies for marginalised youth. This required mechanisms that allowed the partnerships to be flexible and willing to adjust activities as part of the commitment to bringing about societal change.

The reflective perspectives also recognise that the YOUR World Research partnerships and the marginalised youth that we work with function in Change-scapes, landscapes in continual flux and change. There may be fast-changing fragile environments and political systems but also slow-moving embedded social norms and discrimination that sometimes take generations to shift. In this context, partnership is recognised in YOUR World Research at every level, with the marginalised youth, their families and communities, and the broader environmental, cultural, institutional, and political context. Therefore, YOUR World Research planned processes follow our socioecological Change-scape conceptual framework that is also informed by critical realism. Based on the Change-scape, mechanisms are therefore built into research to address power dynamics and help research users to 
listen to the perspectives of children and young people, and so inform policy and practice and ultimately achieve transformational change (Johnson 2015, 2017).

In this Change-scape, spaces for dialogue and mechanisms to support collaboration and commitment to change as a result of participant perspectives were planned. This included mechanisms to co-construct meanings and methods to explore uncertainty with young people so that they found the research interviews meaningful and wanted to continue to engage with us and community members, service providers, and policymakers who might listen. Planning local and provincial verification sessions were key mechanisms in which youth and adults in communities and service providers could debate what is or is not possible to support youth strategies, as were reference groups at national level that have engaged, provided advice, and are now keen to engage in research uptake. We recognise that youth are linked to their context but that they can also be agents of change and create impact.

Partnership building and transforming is impact in itself and the Change-scape conceptual framework is designed to develop partnership and this impact in each stage of the research lifecycle. The depth and breadth of community-university partnerships has grown within and across countries (Banks et al. 2019) and we welcome this article as an opportunity to celebrate that. The different layers of the YOUR World partnership have served as a platform to make steps towards creating impact in a number of areas. Immediately, with academics and practitioners working together on seminar series for discussion about marginalisation and youth with national universities in Nepal and with ministries in Ethiopia; our own partners' programmes in both countries; and in informing policy documents in NGOs and government.

In the longer term, our work with youth and adults in participatory spaces and in dialogue with service providers informs other levels, but will eventually transform the lives of the youth we work with. There are some signs of transformation from youth action; for example, in Nepal as early as one year before project completion, a group of youth from Kathmandu went to demand their rights and services from providers, who were willing to listen. Just as partnerships are layered and change over time, influence and impact are also layered and need to be connected to the realities of the research participants and the changing political systems that we work within.

\section{Notes}

* This issue grew out of the Impact Initiative for International

Development Research which seeks to maximise impact and learning from ESRC-DFID's Joint Fund for Poverty Alleviation Research and their Raising Learning Outcomes in Education Systems Research Programme.

+ 'Insecurity and Uncertainty: Marginalised Young People's Living Rights in Fragile and Conflict Affected Situations in Nepal and 
Ethiopia', funded by ESRC-DFID's Joint Fund for Poverty Alleviation Research [ES/N014391/1 (University of Brighton) and ES/N014391/2 (Goldsmiths, University of London)]. Research also known as Youth Uncertainty Rights (YOUR) World Research: www.gold.ac.uk/anthropology/research/staff/insecurity-anduncertainty/.

- Thank you to the marginalised youth and broader stakeholders YOUR World Research works with in Ethiopia and Nepal. Also to our hard-working international teams: in the UK - Dr Andy West and Signe Gosmann; in Ethiopia - Dr Melese Getu, Amid Ahmed, and Milki Getachew; and in Nepal - Dr Sumon Tuladhar, Shubhendra Shrestha, and Sabitra Neupane. Thanks also to James Georgalakis and the team at the ESRG-DFID-funded Impact Initiative for their support and guidance on research impact and on this article.

1 Principal Investigator (PI) of the ESRG-DFID Joint Fund for Poverty Alleviation Research-funded research on Youth and Uncertainty, Goldsmiths, University of London, UK.

2 Managing Director of CHADET, Ethiopia.

3 Associate Pro-Vice Chancellor for Research and Enterprise, University of Brighton, UK.

4 Executive Director of ChildHope, UK.

5 Organizational Effective Manager, ActionAid Nepal.

6 www.gold.ac.uk/anthropology/research/staff/insecurity-anduncertainty/.

\section{References}

Banks, S. et al. (2019) 'Between Research and Community Development: Negotiating a Contested Space for Collaboration and Creativity', in S. Banks, A. Hart, K. Pahl and P. Ward (eds), Coproducing Research: A Community Development Approach, Bristol: Policy Press

Batsow, S.; Dunleavy, P. and Tinkler, J. (2014) The Impact of the Social Sciences: How Academics and their Research Make a Difference, London: Sage Johnson, V. (2017) 'Moving Beyond Voice in Children and Young People's Participation', Action Research 15.1: 104-24

Johnson, V. (2015) 'Valuing Children's Knowledge: The Politics of Listening', in R. Eyben, I. Guijt, C. Roche and C. Shutt (eds), The Politics of Evidence and Results in International Development: Playing the Game to Change the Rules? Rugby: Practical Action Publishing Johnson, V. (2011) 'Conditions for Change for Children and Young People's Participation in Evaluation: Change-Scape', Child Indicators Research 4.4: 577-96

Johnson, V.; West, A.; Tuladhar, S.; Shrestha, S.M. and Neupane, S. (forthcoming, 2019) 'Marginalised Youth Navigating Uncertainty: Reflections on Co-Construction and Methodology in Nepal', in C. Walker, A. Zoli and S. Zlotowitz (eds), New Ideas for New Times: A Handbook of Innovative Community and Clinical Psychologies, London: Palgrave 
Martikke, S.; Church, A. and Hart, A. (2019) 'A Radical Take on Co-Production? Community Partner Leadership in Research', in S. Banks, A. Hart, K. Pahl and P. Ward (ed.), Coproducing Research: A Community Development Approach, Bristol: Policy Press

Morton, S. (2015) 'Creating Research Impact: The Roles of Research Users in Interactive Research Mobilisation', Evidence and Policy: A Fournal of Research, Debate and Practice 11.1: 35-55

Robson, C. (2002) Real World Research, 2nd ed., Chichester: John Wiley \& Sons 